
\title{
25 Research Square \\ Cardiac variation of internal jugular vein as a marker of volume change in haemorrhagic shock
}

\section{Kurato Tokunaga}

University of Tokyo

Kensuke Nakamura

University of Tokyo

Ryota Inokuchi

University of Tokyo

Rui Terada

University of Tokyo

Yuji Tomioka

University of Tokyo

Ikeda Toshiyuki

University of Tokyo

Etsuko Kobayashi

University ofTokyo

Hitoshi Okazaki

University of Tokyo

Ichiro Sakuma

University ofTokyo

Kent Doi ( $\square$ kdoi-tky@umin.ac.jp )

University of Tokyo

Naoto Morimura

University of Tokyo

\section{Research}

Keywords: cardiac variation, internal jugular vein, collapse index, ultrasound, haemorrhagic shock

Posted Date: January 15th, 2020

DOl: https://doi.org/10.21203/rs.2.20908/v1

License: (c) (1) This work is licensed under a Creative Commons Attribution 4.0 International License.

Read Full License 


\section{Abstract}

Background. Fluid resuscitation is crucial to counter acute haemorrhagic shock and requires prompt and accurate intravascular volume estimation for optimal fluid administration. This study aimed to evaluate whether cardiac variation of the internal jugular vein (IJV), measured by ultrasound, could detect hypovolemic status and predict response to fluid resuscitation.

Methods. Autologous blood transfusion patients for their own elective surgeries were prospectively enrolled at our blood donation centre from August 2014 to January 2015., and movies of vertical B-mode ultrasonography of the IJV were recorded at five points during blood donation, namely, before donation, during donation, end of donation, end of fluid replacement and after hemostasis. Cardiac variation in IJV area and circumference were objectively measured using an automated extraction programme, along with blood pressure and heart rate.

Results. We screened 140patients and data from 104 were eventually evaluated. Among the variables analysed, only collapse index area (Cla) and collapse index circumference (Clc) could detect both intravascular volume loss and response to fluid administration

Conclusions. The cardiac variation of IJV may be a reliable indicator of intravascular volume loss and response to fluid administration in haemorrhagic shock.

\section{Background}

Acute haemorrhagic shock can occur in several different clinical settings, such as in the emergency room, the operating room and the intensive care units, and because early treatment ensures a good clinical course, prompt and accurate assessment of intravascular volume status is essential. However, it can be challenging to accurately recognise hypovolemic status based on physical examination, vital sings and laboratory tests, especially during the early stages of haemorrhagic shock ${ }^{1}$.

Many invasive and noninvasive procedures have been developed for assessing intravascular volume status ${ }^{2}, 3,4$. Pulmonary artery catheterisation (PAC) can measure central venous pressure (CVP), pulmonary artery pressure and pulmonary artery occlusion pressure, and is considered the best procedure for volume status assessment, even though associated complications are its disadvantages ${ }^{5}$. Stroke volume variation (SVV) can be measured less invasively than PAC and is now widely used for predicting fluid responsiveness. Many other devices for volume status assessment have been developed; however, disadvantages in terms of invasiveness and requirement of special equipment remain ${ }^{2}$. Ultrasonography is an easy and useful noninvasive medical imaging technique. Respiration-induced variation in inferior vena cava (IVC) diameter is reported to be a marker of hypovolemic shock and a predictor of fluid responsiveness, and both inspiratory and expiratory IVC diameter correlate with CVP ${ }^{6}$. Additionally, respiratory variation of IVC diameter is expected to be a good parameter that guides fluid therapy ${ }^{7}$. However, IVC measurement may be difficult in some cases because of the excessive presence of fatty 
tissue or bowel gas. In contrast, the IJV can be observed more easily than the IVC, and respiratory variation in IJV is also reported to be useful for the assessment to intravascular volume status ${ }^{8}$.

Blood donation can be used as a model of haemorrhagic shock as it rapidly decreases intravascular volume; however, it is known that vital sings during the procedure show only mild changes, and WHO guidelines for blood donor selection have addressed this issue to prevent complications ${ }^{9}$. Further, respiratory variation of IVC and IJV characteristics have been studied as potential markers of intravascular volume status assessment during blood donation because a decrease in IVC diameter during inspiration and expiration, a change in indirect CVP measurement based on the IJV and significant difference in respiratory variation of IJV, have all been observed after blood donation ${ }^{10,11,12}$. However, these studies suffer from certain problems such as inter-rater reliability and objectivity, and the long recording time required for establishing respiratory variation ${ }^{13,14}$.

We have previously evaluated cardiac variation of the vena cava, which refers to venous vibration that occurs due to changes in cardiac rhythm. This method has the advantage of requiring a shorter recording time than respiratory variation. Therefore, we have developed an automatic image tracking system to analyse changes in IJV, which would be free from inter-rater reliability and objectivity. Previously, we have shown that cardiac variations of IVC and IJV were equally useful for detecting acute intravascular volume change; however, these studies evaluated variation only during dehydration and did not evaluate responsiveness to fluid resuscitation. Additionally, the sample size in these studies was small ${ }^{15,16,17}$. Therefore, we investigated the usefulness of cardiac variation in IJV, not only for detecting reduced intravascular volume but also for predicting the response to fluid resuscitation in autologous blood transfusion patients, who adequately mimicked acute haemorrhage that required immediate fluid replacement.

\section{Methods}

\section{Patients}

This prospective study was conducted from August 2014 to January 2015 at the blood donation centre of The University of Tokyo Hospital. This study was approved by the ethical committee of The University of Tokyo Hospital. Written informed consent was obtained from every participant and all individuals who were autologous blood donors for their own elective surgeries were included in this study. Exclusion criteria were pregnancy, arrhythmia, congenital cardiac anomalies and history of radiotherapy or neck surgery. Individuals with insufficient data were also excluded.

The volume of blood donated was decided based on haemoglobin levels, body weight and height of the individual and all donors were administered $500 \mathrm{ml}$ crystalloid (in 30 minutes) after donation.

Measurements 
The patients were asked to rest in a supine position for few minutes and ultrasonography videos were recorded at 5 points, namely, before donation (T0), halfway during donation (T1), end of donation (T2), during fluid replacement (T3) and after hemostasis (T4). T1 was determined using the real-time volume metre at approximately $200 \mathrm{~mL}$ which represented half the total volume of donation. The ultrasound probe was placed on the skin at a distance of one finger breadth above the right clavicular fossa and was vertically aligned. The IJV was visualised on short-axis views of the horizontal sections in B-mode ${ }^{16}$ and the recording time was 4 seconds during the expiratory phase. Ultrasonography was performed using the SonoSite M-Turbo Ultrasound device (FUJIFILM Sono Site Inc, Tokyo, Japan) and a linear probe (HFL38x/13-6MHz). Imaging was performed by two physicians in the transfusion department and heart rate $(\mathrm{HR})$ and blood pressure $(\mathrm{BP})$ were recorded at all the time points.

Blood vessel boundary images were analysed automatically by the extraction module of the modified software developed at the Graduate School of Engineering, University of Tokyo ${ }^{18}$. The algorithm of the programme is based on snake and speckle tracking models, which is an active contour method that can track objects from the previous image. The area and circumference of the IJV were analysed (Fig 1) and the following parameters were calculated:

1. IJVa Max and IJVa Min: the mean of maximum and minimum IJV area in each cardiac cycle during the expiration phase.

2. IJVc Max and IJVC Min: the mean of maximum and minimum IJV circumference in each cardiac cycle during the expiration phase.

3. Collapse index area (Cla): The mean of (maximum - minimum)/(maximum) of area in each cardiac cycle.

4. Collapse index circumference (Clc): The mean of (maximum -minimum)/(maximum) of circumference in each cardiac cycle.

\section{Statistical analysis}

Data are shown as mean \pm standard deviation or median (interquartile range[IQR]). Statistical analyses were performed using the JMP software (JMP Pro14; SAS Institute Inc, Cary, NC), and 95\% confidence interval $(\mathrm{Cl})$ for each index was calculated. The values at different time points were evaluated using the Wilcoxon rank-sum test and multiple comparisons were adjusted using the Bonferroni method. The correlation of parameters was evaluated using the Spearman correlation test.

\section{Results}

We screened 140 patients for potential enrollment but 36 were excluded because of incomplete data or low ultrasound data quality. Finally, data from 104 patients was analysed in this study. The characteristics of the patients at just before blood donation are summarised in Table 1. 
Table 1

Patient characteristics at the beginning of blood donation

\begin{tabular}{|ll|}
\hline age $(\mathrm{yr})$ & $\mathbf{5 0 . 2} \pm 16.6$ \\
\hline female/male & $84 / 20$ \\
\hline height $(\mathrm{cm})$ & $159 \pm 9$ \\
\hline weight $(\mathrm{kg})$ & $56.5 \pm 11.3$ \\
\hline $\mathrm{BMI}\left(\mathrm{kg} / \mathrm{m}^{2}\right)$ & $22.3 \pm 4.2$ \\
\hline $\mathrm{Hb}(\mathrm{g} / \mathrm{dl})$ & $13.3 \pm 1.4$ \\
\hline donation time $(\mathrm{min})$ & $10 \pm 6$ \\
\hline donation volume $(\mathrm{ml})$ & $389 \pm 24$ \\
\hline HR $(/ \mathrm{min})$ & $77.1 \pm 11.9$ \\
\hline MAP (mmHg) & $87.1 \pm 12.0$ \\
\hline BMI, body mass index; Hb, haemoglobin; HR, heart rate; MAP, mean arterial pressure \\
\hline
\end{tabular}

Data on parameters such as HR, BP, pulse pressure (PP) and the IJV related values for the 5 time points during blood donation are shown in Table 2. These parameters showed similar results in that they changed only in response to blood loss but not after fluid administration. Changes in IJV parameters due to cardiac variation are shown in Table 2 and all parameters showed similar patterns of temporal changes in response to not only blood loss but also to fluid administration. Although no statistically significant difference was observed in the parameters listed in Table 3, Cla and Clc were significantly different even though temporal changes were identical (Table 2). It should be noted that relative change in Cla and Clc in each patient was larger than that of HR, MAP (mean arterial pressure), and PP (Table 3), suggesting relative change of $\mathrm{Cla}$ and $\mathrm{Clc}$ might be sensitive parameter in volume change than $\mathrm{HR}$, MAP and PP. 
Table 2

Changes in clinical parameters, cardiac variation parameters and cardiac variation collapse index of the internal jugular vein during various stages of blood donation

\begin{tabular}{|c|c|c|c|c|c|}
\hline & $\begin{array}{l}\text { T0 } \\
\text { before } \\
\text { donation }\end{array}$ & $\begin{array}{l}\text { T1 } \\
\text { half donation }\end{array}$ & $\begin{array}{l}\text { T2 } \\
\text { all donation }\end{array}$ & $\begin{array}{l}\text { T3 } \\
\text { fluid } \\
\text { replacement }\end{array}$ & $\begin{array}{l}\text { T4 } \\
\text { after } \\
\text { hemostasis }\end{array}$ \\
\hline $\mathrm{HR}(/ \min )$ & $71(64-80)$ & $67(62-76)^{*}$ & $68(62-76) *$ & $67(60-73) *$ & $66(60-76)^{*}$ \\
\hline $\begin{array}{l}\text { MAP } \\
(\mathrm{mmHg})\end{array}$ & $86(79-93)$ & $81(75-88) *$ & $80(73-87) *$ & $79(71-88) *$ & $80(73-88)^{*}$ \\
\hline $\mathrm{PP}(\mathrm{mmHg})$ & $52(43-63)$ & $46(38-56)^{*}$ & $44(37-54)$ * & $48(41-56)$ & $49(39-57)$ \\
\hline Cla (\%) & $\begin{array}{l}15.6(9.7- \\
21.5)\end{array}$ & $\begin{array}{l}18.9(12.5- \\
32.5)^{\star \#}\end{array}$ & $\begin{array}{l}21.0(11.4- \\
35.0)^{\#}\end{array}$ & $\begin{array}{l}14.7(14.7- \\
22.5)\end{array}$ & $\begin{array}{l}17.0(10.0- \\
29.7)\end{array}$ \\
\hline $\mathrm{Clc}(\%)$ & $\begin{array}{l}7.2(4.6- \\
10.1)\end{array}$ & $\underset{* \#}{9.3}(5.5-14.9)$ & $\underset{* \#}{9.5}(5.6-15.0)$ & $6.8(4.6-9.5)$ & $\begin{array}{l}7.9(5.0- \\
12.3)\end{array}$ \\
\hline $\begin{array}{l}\text { IJVa Max } \\
\left(\mathrm{cm}^{2}\right)\end{array}$ & $\begin{array}{l}0.92(0.6- \\
1.42)\end{array}$ & $\begin{array}{l}0.67(0.41- \\
1.06)\end{array}$ & $\begin{array}{l}0.55(0.32- \\
0.86)\end{array}$ & $\begin{array}{l}1.15(0.80- \\
1.49)\end{array}$ & $\begin{array}{l}0.95(0.56- \\
1.42)\end{array}$ \\
\hline $\begin{array}{l}\text { IJVa Min } \\
\left(\mathrm{cm}^{2}\right)\end{array}$ & $\begin{array}{l}0.77(0.46- \\
1.22)\end{array}$ & $\begin{array}{l}0.54(0.27- \\
0.88)\end{array}$ & $\begin{array}{l}0.43(0.20- \\
0.73)\end{array}$ & $\begin{array}{l}0.96(0.63- \\
1.36)\end{array}$ & $\begin{array}{l}0.80(0.40- \\
1.18)\end{array}$ \\
\hline $\begin{array}{l}\text { IJVa Mean } \\
\left(\mathrm{cm}^{2}\right)\end{array}$ & $\begin{array}{l}0.85(0.52- \\
1.34)\end{array}$ & $\begin{array}{l}0.60(0.34- \\
0.97)\end{array}$ & $\begin{array}{l}0.48(0.27- \\
0.76)\end{array}$ & $\begin{array}{l}1.06(0.73- \\
1.45)\end{array}$ & $\begin{array}{l}0.89(0.48- \\
1.31)\end{array}$ \\
\hline $\begin{array}{l}\text { IJVc Max } \\
(\mathrm{cm})\end{array}$ & $\begin{array}{l}4.25(3.63- \\
5.02)\end{array}$ & $\begin{array}{l}3.70(3.07- \\
4.65)\end{array}$ & $\begin{array}{l}3.51(2.68- \\
4.29)\end{array}$ & $\begin{array}{l}4.57(3.93- \\
5.22)\end{array}$ & $\begin{array}{l}4.28(3.43- \\
5.05)\end{array}$ \\
\hline $\begin{array}{l}\text { IJVc Min } \\
(\mathrm{cm})\end{array}$ & $\begin{array}{l}3.94(3.12- \\
4.69)\end{array}$ & $\begin{array}{l}3.35(2.58- \\
4.25)\end{array}$ & $\begin{array}{l}3.11(2.25- \\
3.85)\end{array}$ & $\begin{array}{l}4.26(3.58- \\
5.05)\end{array}$ & $\begin{array}{l}3.98(3.00- \\
4.85)\end{array}$ \\
\hline $\begin{array}{l}\text { IJVc Mean } \\
(\mathrm{cm})\end{array}$ & $\begin{array}{l}4.13(3.28- \\
4.86)\end{array}$ & $\begin{array}{l}3.53(2.84- \\
4.45)\end{array}$ & $\begin{array}{l}3.33(2.51- \\
4.06)\end{array}$ & $\begin{array}{l}4.44(3.75- \\
5.13)\end{array}$ & $\begin{array}{l}4.09(3.25- \\
4.96)\end{array}$ \\
\hline \multicolumn{6}{|c|}{ *, $p<0.001$ vs T0 after Bonferroni correction, ${ }^{*}, p<0.001$ vs T3 after Bonferroni correction } \\
\hline
\end{tabular}


Table 3

Relative changes compared to before donation (T0)

\begin{tabular}{|lllll|}
\hline & $\begin{array}{l}\text { T1 } \\
\text { half donation }\end{array}$ & $\begin{array}{l}\text { T2 } \\
\text { all donation }\end{array}$ & $\begin{array}{l}\text { T3 } \\
\text { fluid replacement }\end{array}$ & $\begin{array}{l}\text { T4 } \\
\text { after hemostasis }\end{array}$ \\
\hline Cla $(\%)$ & $1.27(0.87-1.81)$ & $1.26(0.88-2.19)$ & $0.89(0.67-1.22)$ & $1.09(0.70-1.65)$ \\
\hline Clc $(\%)$ & $1.24(0.89-1.80)$ & $1.36(0.76-2.14)$ & $0.89(0.71-1.22)$ & $1.10(0.68-1.60)$ \\
\hline HR (/min) & $0.94(0.90-1.00)$ & $1.06(1.00-1.11)$ & $0.93(0.88-1.01)$ & $0.93(0.88-0.99)$ \\
\hline MAP (mmHg) & $0.94(0.90-1.00)$ & $0.93(0.89-0.97)$ & $0.93(0.87-0.98)$ & $0.93(0.87-0.99)$ \\
\hline PP (mmHg) & $0.88(0.77-1.04)$ & $0.87(0.73-1.02)$ & $0.93(0.79-1.09)$ & $0.93(0.80-1.07)$ \\
\hline $\begin{array}{l}\text { Cla, collapse index area; Clc, collapse index circumference; HR, heart rate; MAP, mean arterial pressure; } \\
\text { PP, pulse pressure }\end{array}$ & & & \\
\hline
\end{tabular}

The Cla and Clc at T2 (after donation) showed modest but significant correlation with age and BMI (Table 4). Therefore, $\mathrm{Cla}$ and $\mathrm{Clc}$ were stratified according to $\mathrm{BMI}$ (BMI $\geqq 25,25>\mathrm{BMI} \geqq 18.5$ and $18.5>$ $\mathrm{BMI}$ ) and age (age $\geqq 65$ and $65>$ age) and reanalysed. Statistical significance in the temporal changes seen above in Cla and Clc were present only in the $25>\mathrm{BMI} \geqq 18.5$ and the $65>$ age groups (Table 5). This suggested younger patients with normal BMI might show more sensitive response in IJV.

Table 4

Correlation among cardiac variation parameters

\begin{tabular}{|lllll|}
\hline \multicolumn{4}{c}{ Cla } & \multicolumn{3}{c|}{ Clc } \\
\hline & $r$ & $p$ value & $r$ & $p$ value \\
\hline age $(\mathrm{yr})$ & -0.48 & $<0.0001$ & -0.49 & $<0.0001$ \\
\hline $\mathrm{BMl}\left(\mathrm{kg} / \mathrm{m}^{2}\right)$ & -0.32 & 0.0006 & -0.30 & 0.0022 \\
\hline $\mathrm{Hb}(\mathrm{g} / \mathrm{dl})$ & 0.12 & 0.2259 & 0.05 & 0.6304 \\
\hline donation time $(\mathrm{min})$ & 0.10 & 0.2987 & 0.11 & 0.2731 \\
\hline donation volume $(\mathrm{ml})$ & -0.04 & 0.6517 & -0.01 & 0.9289 \\
\hline Cla, collapse index area; Clc, collapse index circumference; BMl, body & mass index; Hb, haemoglobin \\
\hline
\end{tabular}


Table 5

Subgroup analysis of cardiac variation parameters

\begin{tabular}{|c|c|c|c|c|c|}
\hline Cla (\%) & $\begin{array}{l}\text { T0 } \\
\text { before } \\
\text { donation }\end{array}$ & $\begin{array}{l}\text { T1 } \\
\text { half donation }\end{array}$ & $\begin{array}{l}\text { T2 } \\
\text { all donation }\end{array}$ & $\begin{array}{l}\text { T3 } \\
\text { fluid } \\
\text { replacement }\end{array}$ & $\begin{array}{l}\text { T4 } \\
\text { after } \\
\text { hemostasis }\end{array}$ \\
\hline $\mathrm{BMI} \geqq 25(\mathrm{n}=23)$ & $\begin{array}{l}15.0(6.4- \\
27.6)\end{array}$ & $\begin{array}{l}7.9(6.0- \\
17.5)\end{array}$ & $\begin{array}{l}13.0(7.2- \\
21.9)\end{array}$ & $\begin{array}{l}9.3(4.9- \\
22.4)\end{array}$ & $\begin{array}{l}12.4(6.3- \\
27.1)\end{array}$ \\
\hline $\begin{array}{l}25>B M I \geqq 18.5 \\
(n=64)\end{array}$ & $\begin{array}{l}15.6(10.5- \\
20.9)\end{array}$ & $\begin{array}{l}22.0(14.0- \\
33.0)^{\star \#}\end{array}$ & $\begin{array}{l}23.8(11.8- \\
36.2)^{\star \#}\end{array}$ & $\begin{array}{l}14.8(8.8- \\
22.6)\end{array}$ & $\begin{array}{l}15.7(10.6- \\
28.2)\end{array}$ \\
\hline $\begin{array}{l}18.5>\mathrm{BMI}(\mathrm{n}= \\
17)\end{array}$ & $\begin{array}{l}18.4(12.1- \\
31.8)\end{array}$ & $\begin{array}{l}26.2(13.9- \\
35.4)\end{array}$ & $\begin{array}{l}23.2(18.6- \\
48.4)\end{array}$ & $\begin{array}{l}15.2(10.6- \\
22.6)\end{array}$ & $\begin{array}{l}21.6(17.9- \\
31.6)\end{array}$ \\
\hline age $\geqq 65(n=27)$ & $\begin{array}{l}10.8(6.5- \\
20.4)\end{array}$ & $\begin{array}{l}8.3(5.8- \\
21.5)\end{array}$ & $\begin{array}{l}9.5(6.9- \\
18.1)\end{array}$ & $\begin{array}{l}9.2(5.4- \\
21.4)\end{array}$ & $\begin{array}{l}8.0(5.9- \\
19.9)\end{array}$ \\
\hline $65>$ age $(n=77)$ & $\begin{array}{l}16.7(11.2- \\
23.7)\end{array}$ & $\begin{array}{l}22.7(15.3- \\
35.9)^{\#}\end{array}$ & $\begin{array}{l}26.3(16.3- \\
37.7)^{\star \#}\end{array}$ & $\begin{array}{l}15.7(10.1- \\
22.7)\end{array}$ & $\begin{array}{l}19.9(12.5- \\
31.0)\end{array}$ \\
\hline $\mathrm{Clc}(\%)$ & $\begin{array}{l}\text { T0 } \\
\text { before } \\
\text { donation }\end{array}$ & $\begin{array}{l}\text { T1 } \\
\text { half donation }\end{array}$ & $\begin{array}{l}\text { T2 } \\
\text { all donation }\end{array}$ & $\begin{array}{l}\text { T3 } \\
\text { fluid } \\
\text { replacement }\end{array}$ & $\begin{array}{l}\text { T4 } \\
\text { after } \\
\text { hemostasis }\end{array}$ \\
\hline $\mathrm{BMI} \geqq 25(\mathrm{n}=23)$ & $\begin{array}{l}6.6(3.6- \\
10.5)\end{array}$ & $6.6(3.1-8.1)$ & $\begin{array}{l}5.5(3.6- \\
11.5)\end{array}$ & $4.8(3.0-8.8)$ & $\begin{array}{l}6.4(2.8- \\
11.3)\end{array}$ \\
\hline $\begin{array}{l}25>B M I \geqq 18.5 \\
(n=64)\end{array}$ & $\begin{array}{l}7.2(4.9- \\
10.0)\end{array}$ & $\begin{array}{l}10.4(6.6- \\
15.6)^{\star \#}\end{array}$ & $\begin{array}{l}11.2(6.4- \\
16.9)^{\star \#}\end{array}$ & $6.9(4.8-9.7)$ & $\begin{array}{l}7.6(5.0- \\
13.3)\end{array}$ \\
\hline $\begin{array}{l}18.5>\mathrm{BMI}(\mathrm{n}= \\
17)\end{array}$ & $\begin{array}{l}7.9(4.6- \\
12.2)\end{array}$ & $\begin{array}{l}11.5(8.0- \\
16.5)\end{array}$ & $\begin{array}{l}11.5(7.8- \\
22.3)\end{array}$ & $\begin{array}{l}7.3(5.9- \\
10.4)\end{array}$ & $\begin{array}{l}10.8(7.6- \\
13.4)\end{array}$ \\
\hline age $\geqq 65(n=27)$ & $\begin{array}{l}4.6(3.1- \\
9.9)\end{array}$ & $4.4(3.1-8.6)$ & $4.7(2.7-8.2)$ & $4.8(2.8-8.8)$ & $\begin{array}{l}5.2(2.5- \\
7.7)\end{array}$ \\
\hline $65>$ age $(n=77)$ & $\begin{array}{l}8.1(5.4- \\
10.5)\end{array}$ & $\begin{array}{l}11.0(7.4- \\
16.3)^{\star \#}\end{array}$ & $\begin{array}{l}12.0(7.8- \\
18.9)^{\star \#}\end{array}$ & $\begin{array}{l}7.3(4.9- \\
10.5)\end{array}$ & $\begin{array}{l}8.9(5.9- \\
14.1)\end{array}$ \\
\hline
\end{tabular}

\section{Discussion}

Cardiac variation of IJV has not yet been widely evaluated and our results indicate that it is as useful as respiratory variation of IJV in evaluating intravascular volume status. This study demonstrates for the first time that cardiac variation of IJV, measured using an automatic tracing programme, can detect not only intravascular volume loss but also response to fluid administration. Using a clinical model of blood donation by preoperative stable patients is another unique point of this study, because this situation mimics class $\bigotimes$ haemorrhagic shock that was promptly treated by fluid resuscitation. 
Significant changes were observed in cardiac variation of IJV during blood donation and subsequent fluid resuscitation (Table 2), while clinical parameters such as BP and HR could not detect changes in volume status, especially during fluid administration (Table 2), indicating the superiority of cardiac variation indices of IJV over regular vital signs.

Among the cardiac variation parameters evaluated, collapse indices Cla and Clc could better predict change of intravascular volume compared to absolute values of area and circumference, suggesting that interindividual anatomical differences in IJV need to be considered. Additionally, our data show a temporal trend rather than single timepoint change, and this is expected to be better than CVP monitoring described previously 19,20 , because the relative temporal changes in $\mathrm{Cla}$ and $\mathrm{Clc}$ were more sensitive than clinically used parameters such as BP and HR (Table 3).

Several previous studies have investigated the utility of IJV diameter measurement by ultrasonography for intravascular volume assessment during blood donation ${ }^{11,12}$. The reported variation in IVJ area during inspiration and expiration was $47 \pm 18 \%$ before donation and $73 \pm 18 \%$ after donation ${ }^{11}$. Another study has reported on indirect CVP, defined as vertical height of IJV from the point of complete collapse to the sternal angle of Louis detected by ultrasonography plus $5 \mathrm{~cm}$, to be $6.67 \mathrm{~cm}(95 \% \mathrm{Cl} 6.72-7.07)$ before donation and $5.98 \mathrm{~cm}(95 \% \mathrm{Cl} 6.09-6.40)$ after donation ${ }^{12}$. These studies indicate that respiratory variation of IJV might be a reliable indicator of intravascular volume loss.

Previously, we have shown an increase in the collapse index of IVC during dehydration using a passive leg raising test and medical anti-shock trousers ${ }^{15}$. Further, we found a correlation between collapse index of IJV and indirect CVP after dehydration using a sauna ${ }^{16}$; however, these preliminary studies had small sample sizes. Here we show that the collapse index of IJV could be used to monitor dynamic changes in volume status induced by blood loss (200 $400 \mathrm{ml}$ blood donation) and fluid administration ( $500 \mathrm{ml}$ crystalloid), which are clinically more relevant than those observed in our previous studies. Further, the sample size in this study was much larger $(n=104)$, but further investigation is necessary to verify these observations in clinically relevant situations such as haemorrhagic trauma and septic shock.

The image tracking software used enabled the analysis of the collapse index because its variation was small over a short period of time. The advantages of the software developed by us for IJV images are objective assessment and automatic analysis. In contrast, in previous studies, respiratory variation analysis was almost always done by a physician, which may be subject to many biases in each physician's skill set ${ }^{13,14}$. The extraction programme for blood vessel boundary identification from ultrasound data used in this study was based on snake and speckle tracking models, which is an active contour method that can trace objects in the previous image ${ }^{18}$. Importantly, the software can be manually adjusted to mark the exact boundary, if there were inter-rater disagreement in measurement. Software use allows better objective assessment than physician measurements, and the development of software with respect to analysis speed and tracking ability will help improve volume status assessment in the clinical settings. Recently, a wearable ultrasound patch monitor that can continuously measure BP change has been developed, and our results indicate a potential for continuous monitoring of cardiac variation of IVJ 
for intravascular volume evaluation. Future devices that can measure cardiac variation of IVJ continuously will further develop 0volume evaluation technology in the future ${ }^{21}$.

This study has several limitations. First, a comparison of cardiac variation with respiratory variation was not conducted, and many previous studies have reported on the performance of respiratory variation for evaluating intravascular volume loss and fluid challenge response ${ }^{22,23}$. Other clinically available indicators such as CVP, SVV and CRT need to be compared with cardiac variation of IVJ ${ }^{16,25}$. Second, we cannot exclude the possibility that the patients' sympathetic nerve activation might have affected the obtained results. Although the enrolled patients took rest before blood donation, HR decreased just after donation was started, which may be because of relief from psychological stress. Third, age and BMI affected $\mathrm{Cla}$ and $\mathrm{Clc}$; therefore, $\mathrm{Cla}$ and $\mathrm{Clc}$ may not be able to correctly predict fluid status in high and/or low $\mathrm{BMI}$, and older age patients. It is necessary to analyse BMI and age stratified data in a larger cohort.

\section{Conclusion}

The cardiac variation of IJV can be a reliable indicator of intravascular volume loss and response to fluid administration. We employed an automatic tracking programme as it has the advantage of being noninvasive, sensitive and also because it is capable of objective measurement, compared to other clinically used parameters.

\section{Abbreviations}

IVJ: internal jugular vein; Cla: collapse index area; Clc: collapse index circumference; PAC: pulmonary artery catheterisation; CVP: central venous pressure; SVV: stroke volume variation; IVC: inferior vena cava; HR: heart rate; BP: blood pressure; PP: pulse pressure; MAP: mean arterial pressure; IQR: interquartile range; $\mathrm{Cl}$ : confidence interval

\section{Declarations}

\section{Ethics approval and consent to participate}

This prospective study was approved by the ethical committee of The university of Tokyo Hospital.

\section{Consent for publication}

$\mathrm{N} / \mathrm{A}$

\section{Availability of data and materials}

The datasets used and/or analyzed during the current study are available from the corresponding author on reasonable request.

\section{Competing interests}


The authors declare that they have no competing interests.

\section{Funding}

$\mathrm{N} / \mathrm{A}$

\section{Authors' contributions}

$\mathrm{KT}, \mathrm{KN}, \mathrm{RI}, \mathrm{KD}$ conceived and designed the study. KN, RI and KD contributed to data analysis and interpretation of the data and preparation of the manuscript. RY, TI and $\mathrm{HO}$ contributed to the recruitment of participants. TY, EK and IS developed the software automatically extracting blood vessel boundary images. KT wrote the first draft of the manuscript. KN, RI, KD and NM critically reviewed and revised the manuscript for important intellectual content. All authors approved the final version for publication.

\section{Acknowledgements}

$\mathrm{N} / \mathrm{A}$

\section{References}

1. Advanced trauma life support for doctors-student course manual. $8^{\text {th }}$ ed. Chicago: American College of Surgeons; 2008.

2. Sakka SG. Hemodynamic monitoring in the critically III Patient - Current status and perspective. Frontiers in medicine 2015;2:44.

3. Falicov RE, Resnekov L. Relationship of the pulmonary artery end-diastolic pressure to the left ventricular end-diastolic and mean filling pressures in patients with and without left ventricular dysfunction. Circulation 1970;42:65-73.

4. Monnet X, Dres M, Ferre A, Le Teuff G, Jozwiak M, Bleibtreu A, et al. Prediction of fluid responsiveness by a continuous non-invasive assessment of arterial pressure in critically ill patients: comparison with four other dynamic indices. Br J Anaesth 2012;109:330-8.

5. Binanay C, Califf RM, Hasselblad V, O'connor CM, Shah MR, Sopko G, et al. Evaluation study of congestive heart failure and pulmonary artery catheterization effectiveness: the ESCAPE trial. Jama 2005;294:1625-33.

6. Schefold JC, Storm C, Bercker S, Pschowski R, Oppert M, Kruger A, et al. Inferior vena cava diameter correlates with invasive hemodynamic measures in mechanically ventilated intensive care unit patients with sepsis. J Emerg Med 2010;38:632-7.

7. Feissel M, Michard F, Faller JP, Teboul JL. The respiratory variation in inferior vena cava diameter as a guide to fluid therapy. Intensive Care Med 2004;30:1834-7

8. Lipton B. Estimation of central venous pressure by ultrasound of the internal jugular vein. Am J Emerg Med 2000;18:432-4. 
9. Guidelines on Assessing Donor Suitability for Blood Donation World Health Organization; 2012. https://www.ncbi.nlm.nih.gov/books/NBK138218/pdf/Bookshelf_NBK138218.pdf

10. Lyon M, Blaivas M, Brannam L. Sonographic measurement of the inferior vena cava as a marker of blood loss. The American journal of emergency medicine. 2005;23:45-50.

11. Akilli NB, Cander B, Dundar ZD, Koylu R. A new parameter for the diagnosis of hemorrhagic shock: Jugular index. J Crit Care 2012;27:530.e13-8.

12. Unluer $\mathrm{EE}, \mathrm{Kara} \mathrm{PH}$. Ultrasonography of jugular vein as a marker of hypovolemia in healthy volunteers. Am J Emerg Med 2013;31:173-7.

13. Fields JM, Lee PA, Jenq KY, Mark DG, Panebianco NL, Dean AJ. The interrater reliability of inferior vena cava ultrasound by bedside clinician sonographers in emergency department patients. Acad Emerg Med Off J Soc Acad Emerg Med 2011;18:98-101.

14. Saul T, Lewiss RE, Langsfeld A, Radeos MS, Del Rios M. Inter-rater reliability of sonographic measurements of the inferior vena cava. J Emerg Med 2012;42:600-5.

15. Nakamura K, Tomida M, Ando T, Sen K, inokuchi R, kobayashi E, et al. Cardiac variation of inferior vena cava: New concept in the evaluation of intravascular blood volume. J Med Ultrason 2013;40:205-9.

16. Nakamura K, Qian K, Ando T, Inokuchi R, Doi K, kobayashi E, et al. Cardiac variation of internal jugular vein for the evaluation of hemodynamics. Ultrasound Med Biol 2016;42:1764-70.

17. Sonoo T, Nakamura K, Ando T, Sen K, Maeda A, Kobayahsi E, et al. Prospective analysis of cardiac collapsibility of inferior vena cava using ultrasonography. J Crit Care 2015;30:945-8.

18. Qian K, Ando T, Nakamura K, Liao H, Kobayashi E, Yahagi N, et al. Ultrasound imaging method for internal jugular vein measurement and estimation of circulating blood volume. Int J Comput Assist Rad Surg 2014;9:231-9.

19. .Lakhal K, Ehrmann S, Runge I, Benzekri-Lefevre D, Legras A, Dequin PF, et al. Central venous pressure measurements improve the accuracy of leg raising-induced change in pulse pressure to predict fluid responsiveness. Intensive Care Med 2010;36:940-8

20. Magder S. Central venous pressure: A useful but not so simple measurement. Crit Care Med 2006;34:2224-7.

21. Wang C, Li X, Hu H, Zhang L, Huang Z, Lin M, et al. Monitoring of the central blood pressure waveform via a conformal ultrasonic device. Nat Biomed Eng 2018;2:687-95.

22. Preau S, Bortolotti P, Colling D, Dewavrin F, Colas V, Voisin B, et al. Diagnostic Accuracy of the Inferior Vena Cava Collapsibility to Predict Fluid Responsiveness in Spontaneously Breathing Patients With Sepsis and Acute Circulatory Failure. Crit Care Med 2017;45:e290-e7.

23. Long E, Oakley E, Duke T, Babl FE. Does Respiratory Variation in Inferior Vena Cava Diameter Predict Fluid Responsiveness: A Systematic Review and Meta-Analysis. Shock 2017;47:550-9.

24. Deol GR, Collett N, Ashby A, Schmidt GA. Ultrasound accurately reflects the jugular venous examination but underestimates central venous pressure. Chest 2011;139:95-100. 


\section{Figures}

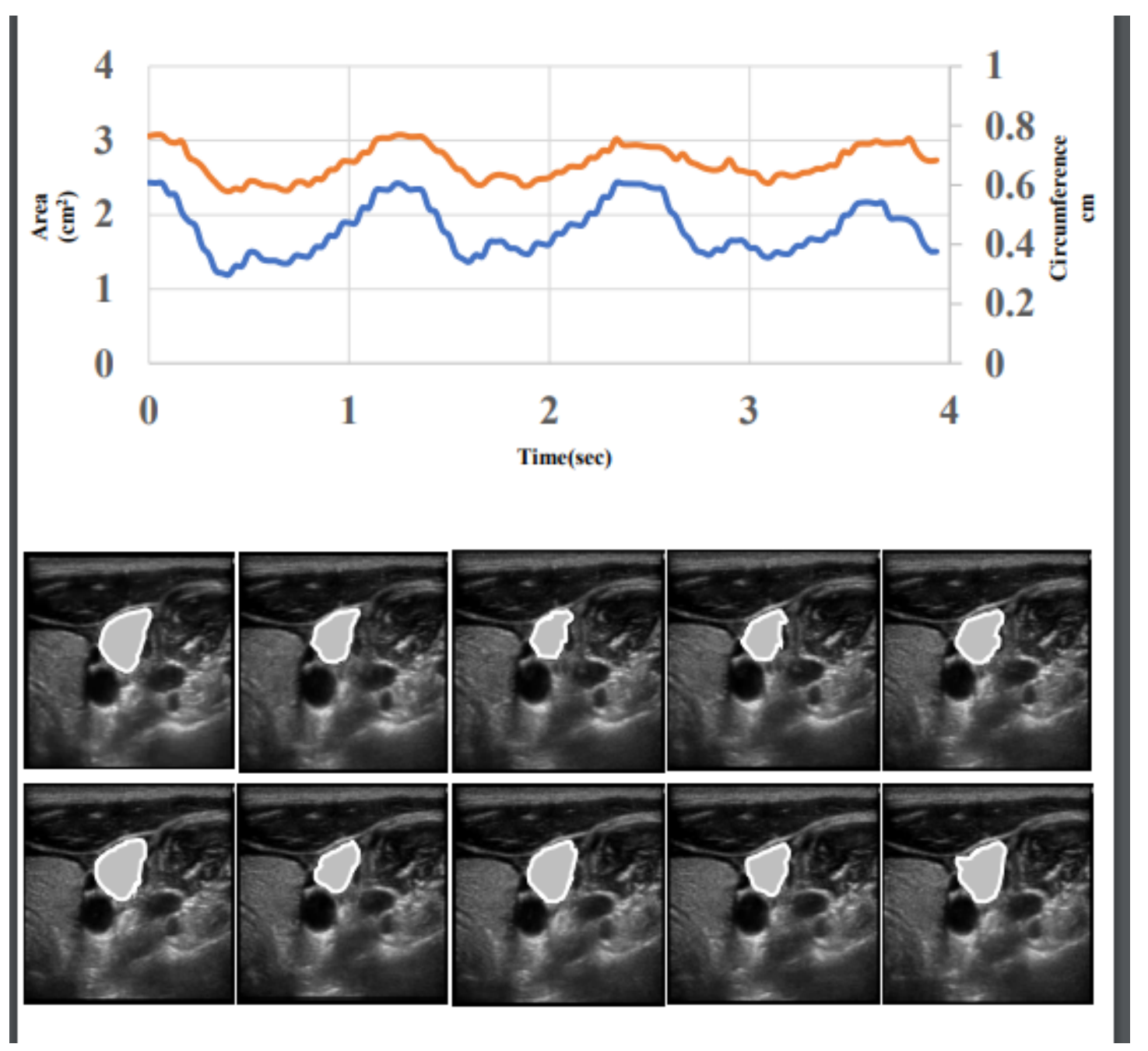

Figure 1

Blood vessel boundary image sampling and automatic tracing The blood vessel boundary images were analysed automatically by the extraction programme based on snake and speckle tracking models. The area (orange line) and circumference (blue line) of the IJV were analysed. 